\title{
Design, Implementation and Performance Analysis of a Dual Axis Solar Tracking System
}

\author{
Ba Thanh Nguyen ${ }^{1}$, Hong-Xuyen Thi $\mathrm{Ho}^{2, *}$ \\ ${ }^{1}$ Faculty of Engineering and Technology, Thu Dau Mot University, Thu Dau Mot City 75109, Vietnam \\ ${ }^{2}$ Faculty of Economics, Ho Chi Minh City University of Technology and Education, Ho Chi Minh City 71307, Vietnam
}

\begin{tabular}{l} 
A R T I C L E I N F O \\
\hline Article history: \\
Received: 09 February, 2020 \\
Accepted: 22 April, 2020 \\
Online: 03 May, 2020 \\
\hline Keywords: \\
Solar Tracking System \\
Servo Motors \\
Arduino
\end{tabular}

A B S T R A C T
This study presents the design and construction of the Dual Axis Solar Tracking System to
ensure maximum energy gain. The solar tracking system will automatically follow the sun's
position to maximize the intensity of the light emitted from the sun. When the light intensity
decreases, the system automatically changes its direction to get the maximum light intensity.
Light Dependent Resistor (LDR) is used to track the coordinates of the sun. The two servo
motors that receive signals from the central processing unit will turn the solar panel to the
appropriate location for optimum performance. The energy results obtained by the dual-
axis solar system are compared with single and fixed solar systems. This research provides
optimal solar energy usage.

\section{Introduction}

Nowadays, environmental pollution is getting more serious, traditional energy sources such as oil, coal, etc. are gradually exhausted. However, the global demand for energy is forecasted to increase in the upcoming decades. Thus, many countries are promoting the development of alternative energy sources [1].

Renewable energy is an energy source that does not consume the limited resources of the earth. It can be easily and quickly replenished. Renewable energy plays an important role in meeting energy demand and contributing to climate change control [2].

Among renewable energy sources such as solar energy, wind energy, biomass energy, tidal energy, etc., Solar energy can be easily exploited in Vietnam because Vietnam has a high level of radiation, and advances in solar technology have made production costs more and more affordable [3] [4].

Because the earth is always orbiting its axis, the angle of sunlight is constantly changing, affecting the amount of solar radiation that is projected on the solar cell. To increase the efficiency of absorbing light from the sun, we need a system of devices called the solar tracking system that help the photovoltaic panels orientate to the sun.

The solar tracking system includes tracking installation system, solar panels and tracking control system. The mounting structure

\footnotetext{
*Corresponding Author: Hong-Xuyen Thi Ho, xuyenhth@hcmute.edu.vn
}

is the body of the system, and the control system is its brain, which controls the movement of the solar panel system.

Many authors have studied solar tracking. Mayank Kumar Lokhande [5] presented an automatic solar tracking system. The study designed a microcontroller-based solar panel tracking system and observed that the single-axis solar tracking unit increased efficiency by $30 \%$ compared to the fixed panel.

Guiha Li, Runsheng Tang and Hao Zhong [6] experimented with a single horizontal solar tracking system. The study found that the east-west-oriented system was not significantly improved while the south-north oriented system was the best. The efficiency increase for the east-west axis is below $8 \%$ while for the southnorth axis it increases $10-24 \%$.

Chaiko and Rizk [7] have developed an effective solar tracking system. The authors designed a simple axis tracking system by using a stepper motor and light sensor. They observed that this system increased the efficiency of collecting energy by keeping a solar panel perpendicular to the sun's rays. The study also found that the electrical power increased by $30 \%$ compared to static systems.

Imam Abadi, Adi Soeprijanto and Ali Musyafa [8] designed a single-axis solar tracking system based on fuzzy logic. They performed on ATMEGA 8353 microcontroller to improve the power of the panels. The study presented that the performance of solar tracking systems with fuzzy control increased by $47 \%$ compared to static systems. 


\section{B.T. Nguyen et al. / Advances in Science, Technology and Engineering Systems Journal Vol. 5, No. 3, $41-45$ (2020)}

Ashwin R, Varun A.K et al. [9] showed a single-axis solar tracking system based on sensors to achieve the highest energy level. The system automatically changes in the direction of solar panel to get maximum light energy. Therefore, the test results show the robustness and productivity of the proposed method.

In 2013, Anusha, Chandra and Reddy [10] designed a solar tracking system based on a real-time clock. They compared a static system and a real-time system using an ARM processor. Experiments have proven that the new system is about $40 \%$ more efficient.

Hussain S. Akbar [11] designed a single-axis solar tracking unit using the AVR microcontroller. The results show that the designed solar tracking system has improved the output power by $18-25 \%$ compared to the static panels in Kirkuk, Iraq.

In 2016, H. Fathabadi [12] tested that the energy level obtained from the dual-axis solar tracking system was $28.8 \%$ - $43.6 \%$ higher than static systems depending on the season.

Jing-Min Wang and Chia-Liang Lu [13] implemented a dualaxis solar tracking system in New Taipei City, Taiwan. Experiments show that their system boosts energy levels to $28.31 \%$ for a cloudy day.

Munna, M. S et al. [14] constructed and evaluated the performance of dual-, single- and fixed-axis solar tracking systems, the data showed that the dual-axis system is more optimal than the two systems. again.

Mustafa, F. I. et al. [15] implemented a dual-axis solar system, data collected in one day showed that the efficiency of this system is $35 \%$ higher than that of fixed systems.

The authors Chhoton, AC, and Chakraborty, N. R [16] performed a performance evaluation of the dual-axis solar tracking system, the data collected during the day showed that the performance of this system was higher than the fixed system. $40 \%$.

In this study, the authors designed and constructed a dual-axis solar tracking system with a simple and low-cost structure that still meets the requirements of increasing the efficiency of solar energy exploitation. The automatic operating system is controlled by Arduino microcontroller. The results of this study provide optimal solar energy solutions. Moreover, the results of this study provide an optimal solution for solar energy, helping to improve the efficiency of the solar power system, effectively serving the energy production process.

This paper is organized as follows. Part 2 discusses the operating principles of a solar tracking system. Part 3 presents hardware and software design. Part 4 presents the test results, compared with the static system. The last part is the conclusion.

\section{Overview of Solar Tracking System}

\subsection{A Solar Tracker}

The solar tracking system was created to take advantage of solar radiation as efficiently as possible, increasing the amount of energy radiated to the solar rig. Thus, the amount of electricity generated will be greater than the fixed devices [17].

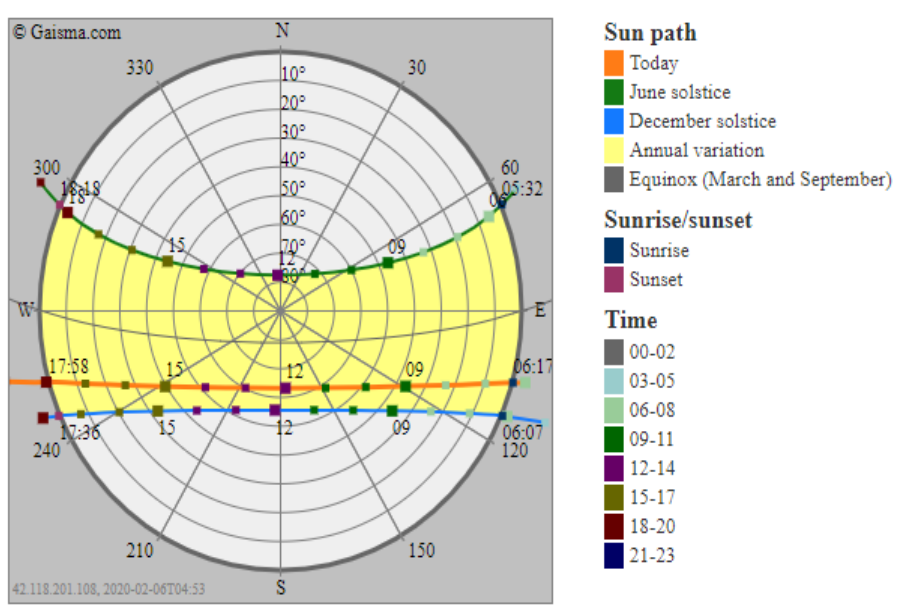

Figure 1: Sun path in Thu Dau Mot City, Vietnam [18]

A solar tracking system consists of three components: a mechanical mechanism, a solar panel and a control system.

\subsection{Types of solar tracking}

Solar tracking system plays an important role in the development of solar energy applications, in order to improve the efficiency of solar power systems.

According to the mechanical structure, the solar tracking system has 2 types: single and dual-axis systems [12], [19]. Of these, dual shafts are often used because it provides higher accuracy and is known to improve solar power captured capacity compared to single-axis tables [13]. In addition, there is a way to classify according to control with a positive and passive system [79].

\subsubsection{One-Axis Trackers}

The single-axis solar tracking system uses an inclined PV mount bracket and an electric motor to move the board in orbit closer to the position of the sun. Spindle can be horizontal, vertical or inclined. Figure 2 shows a general diagram of a single-axis tracker that shows both the axis of rotation (unit vector e) and the collector plane (the unit vector is normal for the collector plane). The angle between these two unit vectors is usually kept constant in this type of solar tracker.

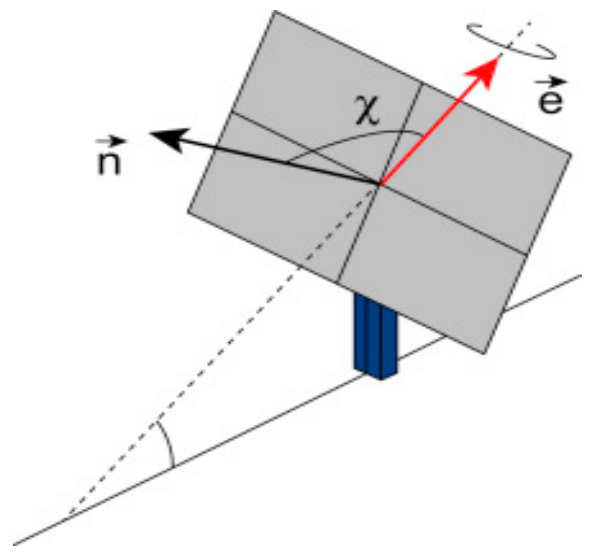

Figure 2: Characteristic vectors in a one-axis tracker [19]. 


\subsubsection{Two-Axis Trackers}

The two-axis solar tracking system can achieve the maximum power level because, because it is completely free to move in two directions, it is capable of tracking the sun anywhere.

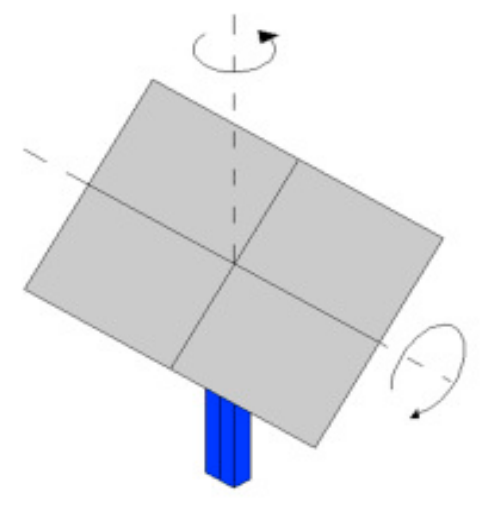

Figure 3: Characteristic movements in a two-axis tracker [19]

\section{Proposed Solar Tracker System}

\subsection{Architecture of The Overall System}

Our proposed design is a dual-axis solar tracking system, based on feedback loops. The system consists of optical resistors acting as sensors, servo motors, actuators, and Arduino microcontrollers. The whole system is divided into two main parts: hardware and software. The main equipment is listed in Table 1 and the system has diagrams as shown in Figure 4.

Table 1: List of devices

\begin{tabular}{|l|l|c|}
\hline No. & \multicolumn{1}{|c|}{ Item Name } & Quantity \\
\hline 1 & Arduino Uno R3 & 1 \\
\hline 2 & MG996R Servo Motor & 2 \\
\hline 3 & Light Dependent Resistor & 4 \\
\hline 4 & Module LM2596 & 2 \\
\hline 5 & Solar Panel 10 W & 1 \\
\hline 6 & Solar Charge Controller & 1 \\
\hline 7 & Battery 12V 5Ah/10HR & 1 \\
\hline 8 & $\begin{array}{l}\text { DSN-VC288 DC 100V 10A Voltmeter } \\
\text { Ammeter }\end{array}$ & 1 \\
\hline
\end{tabular}

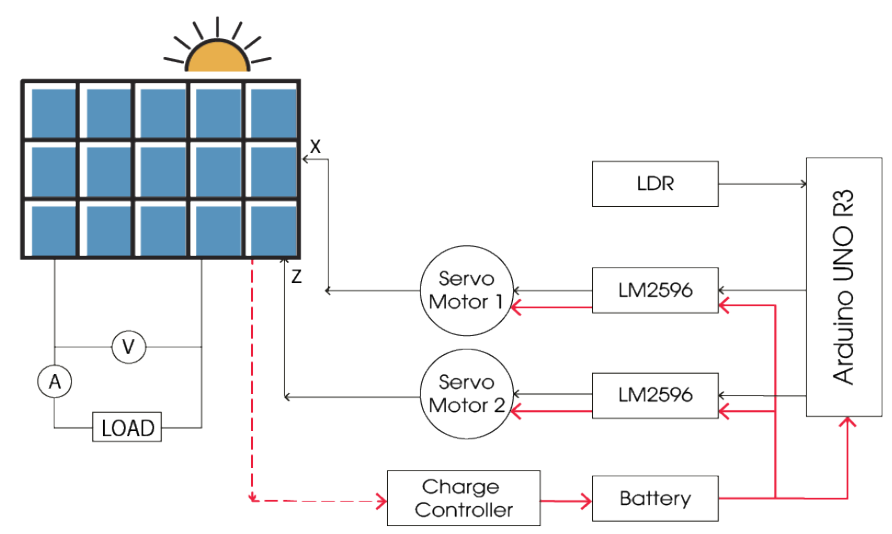

Figure 4: Block diagram of overall system

\subsection{Hardware Design}

Figure 3 depicts the structure of the model including 2 main components: fixed and mobile parts. Fixed parts are the base of the system; the movable joint is attached to the servo motor, placed above and below to rotate the solar panels in two directions.

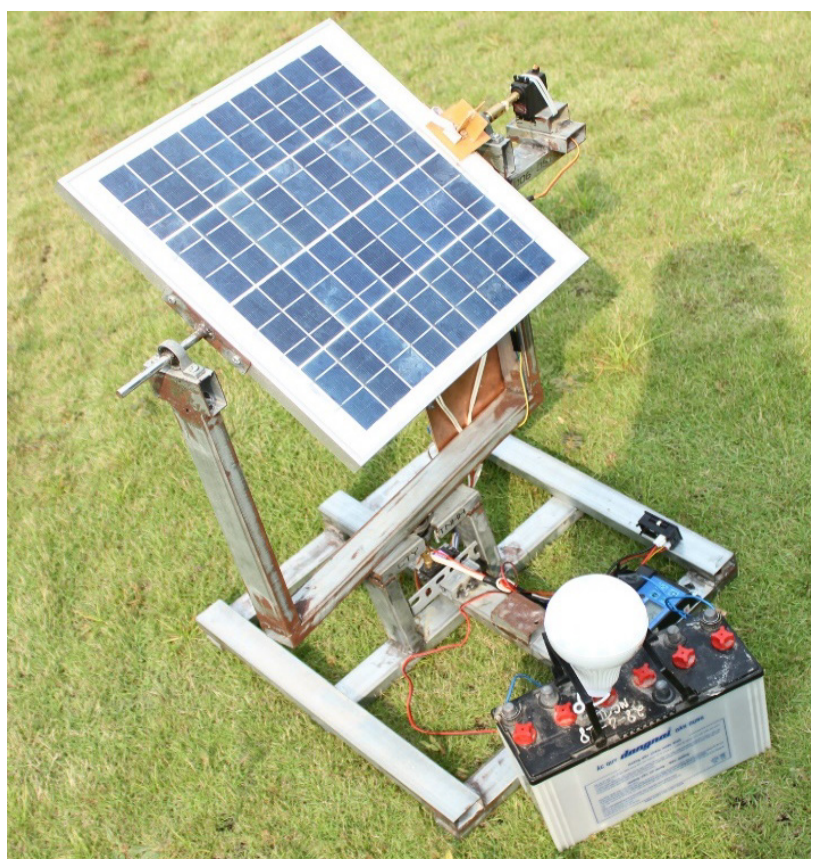

Figure 5: Complete hardware setup of a solar tracking system

\subsection{Software Design}

The sensor system consists of 4 resistors (R1, R2, R3, R4) that will receive light from the light source. Between these 4 resistors, there will be a cross-shaped partition dividing the 4 optical sensors into 4 different directions. This partition will serve as a guide for the 4 optical barriers always towards the strongest light source, namely the sun. When the sensor assembly is perpendicular to the radiation of the sun, the values of the 4 sensors will be equal.

The signal from the sensor assembly will be transmitted directly to the Arduino control center and converted into a digital signal. Here, the Arduino compares the average of the two adjacent optical sensors to the average of the two opposite sensors.

$$
\begin{aligned}
& \mathrm{A}=(\mathrm{R} 1+\mathrm{R} 2) / 2 \\
& \mathrm{~B}=(\mathrm{R} 3+\mathrm{R} 4) / 2 \\
& \mathrm{C}=(\mathrm{R} 1+\mathrm{R} 3) / 2 \\
& \mathrm{D}=(\mathrm{R} 2+\mathrm{R} 4) / 2
\end{aligned}
$$

For R1, R2, R3, R4 are the resistance values of the 4 optical resistors LDR1, LDR2, LDR3, LDR4, respectively. These values are inversely proportional to the values of voltage transferred to the Arduino.

If $\mathrm{A}=\mathrm{B}$, the servo motor controls the $\mathrm{X}$-axis.

If $\mathrm{C}=\mathrm{D}$, then the $\mathrm{Z}$-axis servo motor is stationary.

If $\mathrm{A}>\mathrm{B}$, it means that the light is more concentrated on R3, R4 side, 1st servo motor rotates the panel downwards until the light is perpendicular to the panel then stops. 
If $\mathrm{A}<\mathrm{B}$, which means more light is concentrated on $\mathrm{R} 1, \mathrm{R} 2$ side, 1st servo motor rotates the panel upwards until the light is perpendicular to the panel then stops.

Similarly, if C> D, which means more focused light on side $\mathrm{R} 2$, R4, servo motor 2 will rotate the solar panel to the right until the light is perpendicular to the solar panel.

If $\mathrm{C}<\mathrm{D}$, it means that the light on the side of $\mathrm{R} 1$ and $\mathrm{R} 3$ is more concentrated, the servo motor 2 will rotate the battery plate to the left until the light is perpendicular to the solar panel, then stop.

The rotation angle of servo motors is within the limit of $0-180$ degrees.

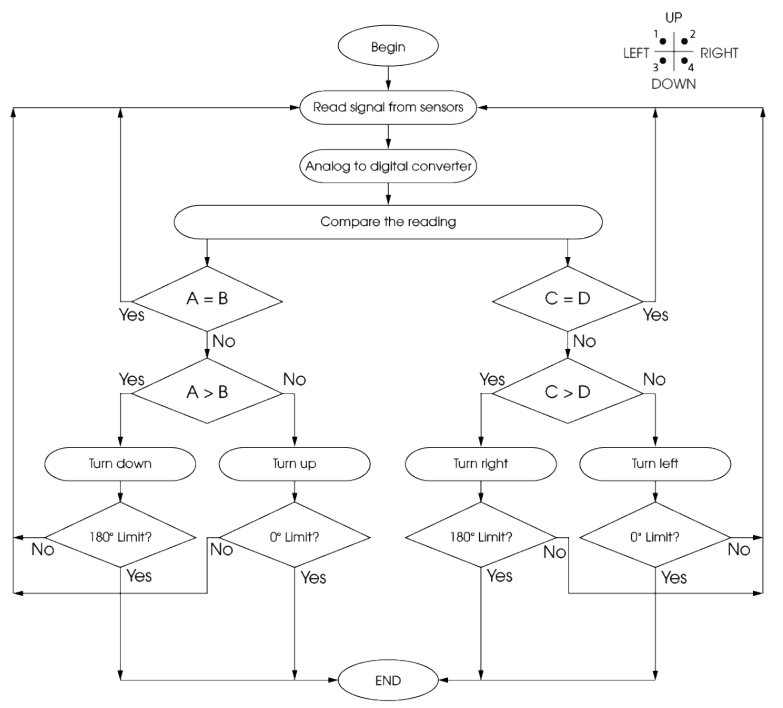

Figure 6: Flowchart of Solar Tracking System

\section{Experimental Setup and Results}

This study has implemented experiments for three systems: fixed solar panels, single-axis solar tracking system, and dual-axis solar tracking system. The experiment was conducted on December 12,2019 , from 6:30 to $18: 30$, the weather was sunny and cloudy at the location $10^{\circ} 58^{\prime} 49.8$ "N $106^{\circ} 40^{\prime} 26.4 " \mathrm{E}$.

In this experiment, we use the DSN-VC288 DC 100V 10A Voltmeter Ammeter to measure the amperage and voltage produced by the solar panel for a load (9W LED). From the recorded data, the authors use the Excel software to calculate the power output (Table 2) and plot the chart as Figure 7.

Table 2 shows the statistical results for the three systems, and these results are plotted as shown in Figure 7. Experimental results in the dual-axis tracking system have a total output of more than $14.28 \mathrm{~W}(20,77 \%)$ compared to a single-axis tracking system and $20.31 \mathrm{~W}(32.39 \%)$ more when the solar panel is left standing. Thus, the use of the dual-axis solar battery tracking system will have a greater efficiency than leaving the battery in place and tracking a single axis.

As shown in Figure 7, the performance of the dual axis system is more optimal than that of a single and fixed system. The graph descended at 11 o'clock because of the cloud cover, at 11 o'clock a cloud appeared to cover the sun, so the output power of all 3 systems decreased.
Table 2: Data for different solar tracker

\begin{tabular}{|c|c|c|c|}
\hline $\begin{array}{l}\text { Time } \\
\text { (h: } \\
\text { mm) }\end{array}$ & $\begin{array}{l}\text { Fixed Panel } \\
\text { (Watt) }\end{array}$ & $\begin{array}{c}\text { Single Axis } \\
\text { Tracker } \\
\text { (Watt) }\end{array}$ & $\begin{array}{c}\text { Dual Axis } \\
\text { Tracker } \\
\text { (Watt) }\end{array}$ \\
\hline $6: 30$ & 0 & 0 & 0 \\
\hline $7: 00$ & 0,16 & 0,16 & 0,32 \\
\hline $7: 30$ & 0,415 & 0,24 & 0,67 \\
\hline $8: 00$ & 0,765 & 0,32 & 2,27 \\
\hline $8: 30$ & 1,2 & 0,49 & 4,12 \\
\hline 9:00 & 4,6 & 5,04 & 6,26 \\
\hline $9: 30$ & 4,7 & 5,04 & 6,95 \\
\hline 10:00 & 6,3 & 7,27 & 7,84 \\
\hline $10: 30$ & 6,84 & 7,08 & 8,06 \\
\hline 11:00 & 1,58 & 1,69 & 1,8 \\
\hline $11: 30$ & 6,25 & 7,48 & 8,1 \\
\hline $12: 00$ & 6,25 & 7,48 & 8,1 \\
\hline $12: 30$ & 6 & 6,25 & 7,02 \\
\hline $13: 00$ & 6,8 & 7,12 & 7,52 \\
\hline $13: 30$ & 3,6 & 5,15 & 5,61 \\
\hline 14:00 & 1,8 & 1,89 & 2,18 \\
\hline $14: 30$ & 0,9 & 1,09 & 1,27 \\
\hline $15: 00$ & 1,26 & 1,13 & 1,39 \\
\hline $15: 30$ & 0,99 & 1,11 & 1,39 \\
\hline $16: 00$ & 0,8 & 0,91 & 1,1 \\
\hline $16: 30$ & 0,57 & 0,729 & 0,9 \\
\hline $17: 00$ & 0,45 & 0,49 & 0,59 \\
\hline $17: 30$ & 0,24 & 0,3 & 0,37 \\
\hline 18:00 & 0,236 & 0,29 & 0,29 \\
\hline $18: 30$ & 0 & 0 & 0 \\
\hline Total & 62.706 & 68.74 & 83.02 \\
\hline
\end{tabular}




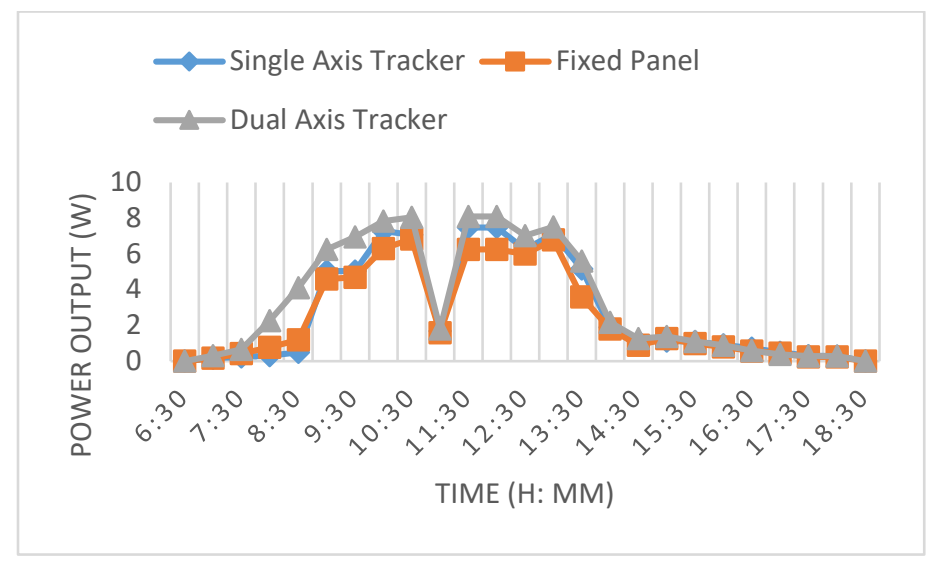

Figure 7: Graphical comparison of experimental data

\section{Conclusion}

Solar energy is an important renewable energy source. To get maximum solar energy, the solar tracking system is needed. In this study, the authors designed a solar tracking system that uses photoresists, Arduino microcontrollers, and servomotors. The research results show that the dual-axis solar tracking system is more optimal than the other systems, with an outstanding performance of $20.77 \%$ compared to the single-axis and $32.39 \%$ compared to fixed solar panels. The results show that this solar tracking system is a low cost, efficient and easily implementable. In the future, the study will improve the hardware with the display of time, voltage, current, power via LCD and export data via wifi network.

\section{Conflict of Interest}

The authors declare no conflict of interest.

\section{Acknowledgment}

The authors appreciate the support from Thu Dau Mot University and Ho Chi Minh City University of Technology and Education in Vietnam.

\section{References}

[1] Rezvani, A., Gandomkar, M., Izadbakhsh, M., \& Ahmadi, A. (2015). Environmental/economic scheduling of a micro-grid with renewable energy resources. Journal of cleaner production, 87, 216-226.

[2] Mallick, T. C., Munna, M. S., Barua, B., \& Rahman, K. M. (2014, October). A design \& implementation of a single axis solar tracker with diffuse reflector. In 2014 9th International Forum on Strategic Technology (IFOST) (pp. 289293). IEEE.

[3] Polo, J., Bernardos, A., Navarro, A. A., Fernandez-Peruchena, C. M., Ramírez, L., Guisado, M. V., \& Martínez, S. (2015). Solar resources and power potential mapping in Vietnam using satellite-derived and GIS-based information. Energy Conversion and Management, 98, 348-358.

[4] The World Bank. Global Solar Atlas version 2.0 (on 23-Oct-2019) https://globalsolaratlas.info/download/vietnam

[5] Lokhande, M. K. (2014). Automatic solar tracking system. International Journal of Core Engineering and Management, 1(7), 122-133.

[6] Li, G., Tang, R., \& Zhong, H. (2012). Optical performance of horizontal single-axis tracked solar panels. Energy Procedia, 16, 1744-1752.

[7] Rizk, J. C. A. Y., \& Chaiko, Y. (2008). Solar tracking system: more efficient use of solar panels. World Academy of Science, Engineering and Technology, 41, 313-315.

[8] I. Abadi, A. Soeprijanto and A. Musyafa (2014). Design of single axis solar tracking system at photovoltaic panel using fuzzy logic controller. 5th Brunei
International Conference on Engineering and Technology (BICET 2014), Bandar Seri Begawan, pp. 1-6.

[9] Ashwin R, JoshuaraI Immanuel K, Lalith Sharavn C, Ravi Prasad P.S, Varun A.K (2014). Design and Fabrication of Single Axis Solar Tracking System Journal of Mechanical and Production Engineering ISSN: 2320-2092, Volume- 2, Issue-12.

[10] Anusha, K., \& Reddy, S. C. M. (2013). Design and development of real time clock based efficient solar tracking system. International Journal of Engineering Research and Applications, 3(1), 1219-1223.

[11] Hussian S. Akbar, Muayyad N. Fathallah, Ozlim O. Raoof (2017). Efficient Single Axis Tracker Design for Photovoltaic System Applications. IOSR Journal of Applied Physics 09(02):53-60

[12] Fathabadi, H. (2016). Novel high accurate sensorless dual-axis solar tracking system controlled by maximum power point tracking unit of photovoltaic systems. Applied Energy, 173, 448-459.

[13] Wang, J. M., \& Lu, C. L. (2013). Design and implementation of a sun tracker with a dual-axis single motor for an optical sensor-based photovoltaic system. Sensors, 13(3), 3157-3168.

[14] Munna, M. S., Bhuyan, M. A. I., Rahman, K. M., \& Hoque, M. A. (2015, September). Design, implementation and performance analysis of a dual-axis autonomous solar tracker. In 2015 3rd International Conference on Green Energy and Technology (ICGET) (pp. 1-5). IEEE.

[15] Mustafa, F. I., Shakir, S., Mustafa, F. F., \& Naiyf, A. T. (2018, March). Simple design and implementation of solar tracking system two axis with four sensors for Baghdad city. In 2018 9th International Renewable Energy Congress (IREC) (pp. 1-5). IEEE.

[16] Chhoton, A. C., \& Chakraborty, N. R. (2017, September). Dual axis solar tracking system-A comprehensive study: Bangladesh context. In 2017 4th International Conference on Advances in Electrical Engineering (ICAEE) (pp. 421-426). IEEE.

[17] Jovanovic, V. M., Ayala, O., Seek, M., \& Marsillac, S. (2016, March). Single axis solar tracker actuator location analysis. In SoutheastCon 2016 (pp. 1-5). IEEE.

[18] Thu Dau Mot Vietnam-Sunrise, sunset, dawn and dusk times: https://www.gaisma.com/en/location/thu-dau-mot.html

[19] Reca-Cardeña, J., \& López-Luque, R. (2018). Design Principles of Photovoltaic Irrigation Systems. In Advances in Renewable Energies and Power Technologies (pp. 295-333). Elsevier. 